\title{
Improved representation of particle size and solubility in model simulations of atmospheric dispersion and wet- deposition from Fukushima
}

Article

Accepted Version

Creative Commons: Attribution-Noncommercial-No Derivative Works 4.0

Dacre, H., Bedwell, P., Hertwig, D., Leadbetter, S., loizou, P. and Webster, H. (2020) Improved representation of particle size and solubility in model simulations of atmospheric dispersion and wet-deposition from Fukushima. Journal of Environmental Radioactivity, 217. 106193. ISSN 0265-931X doi: https://doi.org/10.1016/j.jenvrad.2020.106193 Available at https://centaur.reading.ac.uk/88957/

It is advisable to refer to the publisher's version if you intend to cite from the work. See Guidance on citing.

To link to this article DOI: http://dx.doi.org/10.1016/j.jenvrad.2020.106193

Publisher: Elsevier

All outputs in CentAUR are protected by Intellectual Property Rights law, including copyright law. Copyright and IPR is retained by the creators or other copyright holders. Terms and conditions for use of this material are defined in the End User Agreement. 


\section{www.reading.ac.uk/centaur}

\section{CentAUR}

Central Archive at the University of Reading

Reading's research outputs online 


\title{
Improved representation of particle size and solubility in model simulations of atmospheric dispersion and wet-deposition from Fukushima
}

\author{
H. F. Dacre ${ }^{\mathrm{a}}$, P. Bedwell ${ }^{\mathrm{b}}$, D. Hertwig ${ }^{\mathrm{a}}$, S. J. Leadbetter ${ }^{\mathrm{c}}$, P. Loizou ${ }^{\mathrm{a}}$, H. N. Webster ${ }^{\mathrm{c}, \mathrm{d}}$ \\ ${ }^{a}$ University of Reading, $U K$ \\ ${ }^{b}$ Public Health England, UK \\ ${ }^{c}$ Met Office, UK \\ ${ }^{d}$ College of Engineering, Mathematics and Physical Sciences, University of Exeter, Exeter, UK
}

\begin{abstract}
Radionuclides released into the atmosphere following the Fukushima Dai-ichi Nuclear Power Plant (FDNPP) accident were detected by ground-based monitoring stations worldwide. The inter-continental dispersion of radionuclides provides a unique opportunity to evaluate the ability of atmospheric dispersion models to represent the processes controlling their transport and deposition in the atmosphere. Co-located measurements of radioxenon $\left({ }^{133} \mathrm{Xe}\right)$ and caesium $\left({ }^{137} \mathrm{Cs}\right)$ concentrations enable individual physical processes (dispersion, dry and wet deposition) to be isolated. In this paper we focus on errors in the prediction of ${ }^{137} \mathrm{Cs}$ attributed to the representation of particle size and solubility, in the process of modelling wet deposition. Simulations of ${ }^{133} \mathrm{Xe}$ and ${ }^{137} \mathrm{Cs}$ concentrations using the UK Met Office NAME (Numerical Atmospheric-dispersion Modelling Environment) model are compared with CTBTO (Comprehensive Nuclear-Test-Ban Treaty Organisation) surface station measurements. NAME predictions of ${ }^{137} \mathrm{Cs}$ using a bulk wet deposition parameterisation (which does not account for particle size dependent scavenging or solubility) significantly underestimate observed ${ }^{137} \mathrm{Cs}$. When a binned wet deposition parameterisation is implemented (which accounts for particle size dependent scavenging) the correlations between modelled and observed air concentrations improve at all 9 of the Northern Hemisphere sites studied and the respective RMSLE (root-mean-square-log-error) decreases by a factor of 7 due to a decrease in the wet-deposition of Aitken and Accumulation mode particles. Finally, NAME simulations were performed in which insoluble submicron particles are represented. Representing insoluble particles in the NAME simulations improves the RMSLE at all sites further by a factor of 7 . Thus NAME is able to predict ${ }^{137} \mathrm{Cs}$ with good accuracy (within a factor of 10 of observed ${ }^{137}$ Cs values) at distances greater than $10,000 \mathrm{~km}$ from FDNPP only if insoluble submicron particles are considered in the description of the source. This result provides further evidence of the presence of insoluble Cs-rich microparticles in the release following the accident at FDNPP and suggests that these small particles travelled across the Pacific Ocean to the US and further across the North Atlantic Ocean towards Europe.
\end{abstract}

Keywords: Fukushima, Wet Deposition, Caesium, Xenon, Particle size, Solubility

Email address: h.f.dacre@reading.ac.uk () 


\section{Introduction}

A range of radionuclides are produced by nuclear reactors as a by-product of nuclear fission. Were there to be an accident at a nuclear reactor, some of this radioactive material may be inadvertently released into the environment. Predicting the dispersion and deposition of radionuclides released into the atmosphere following a nuclear accident is of great importance as they may present a risk to human health and the environment $[1,2]$. Lagrangian particle dispersion models are used as the basis for such emergency response predictions. For example, public health agencies (such as Public Health England, Institute for Radiological Protection and Nuclear Safety and Federal Office for Radiation Protection) use dispersion model output to estimate dose from internal and external exposure to passing radioactive plumes. These dose estimates form part of the scientific and technical advice provided to support government decision makers during emergencies. The aim of this paper is to examine the ability of the Met Office's atmospheric dispersion model (NAME) to accurately represent the processes affecting the transport and removal of radionuclides from the atmosphere over inter-continental scales, specifically the parameterisation of wet deposition.

On 11 March 2011 an earthquake off the Pacific coast of Tohoku, Japan, triggered a powerful tsunami. The tsunami resulted in a loss of power and the resultant loss of cooling caused a nuclear accident at the Fukushima Dai-ichi Nuclear Power Plant (FDNPP) [3]. Radionuclides were released into the atmosphere and were detected at a network of measurement sites across the globe. Previous attempts to understand the transport and deposition of ${ }^{137} \mathrm{Cs}$ emitted from FDNPP have been made in several modelling studies on a Japanese scale $[4,5,6]$ and a global scale $[7,8]$. In these studies, simulated ${ }^{137} \mathrm{Cs}$ air concentration and ${ }^{137} \mathrm{Cs}$ deposition to the surface have been found to differ substantially from the observed values, and between simulations [5]. The processes controlling environmental concentrations of ${ }^{137} \mathrm{Cs}$ include (i) the emission rate, (ii) transport to receptor, (iii) loss due to removal (dry and wet deposition) and (iv) loss due to radioactive decay. Errors in the model representation of these processes are multiplicative which means that disentangling errors due to individual factors is not straightforward [9].

Caesium is a highly reactive isotope which can readily attach to particles in the atmosphere such as ammonium, sulfate and nitrate [10]. It is typically assumed that ${ }^{137} \mathrm{Cs}$ is subject to the same dispersion and removal processes as these soluble particles. Thus ${ }^{137} \mathrm{Cs}$ is usually treated as soluble in dispersion modelling forecasts $[11,8,12]$. Since wet deposition is often the predominant removal mechanism of particles in the atmosphere $[13,14,15]$, several modelling studies have investigated the sensitivity of their simulations to uncertainty in the empirical scavenging parameters used in their parameterisations $[4,6]$. Simulations of ${ }^{137} \mathrm{Cs}$ in the environment are highly sensitive to these scavenging parameter choices [16], but no single set of scavenging parameters has been found to result in systematically better agreement with observed ${ }^{137} \mathrm{Cs}$ than the others. If precipitation fields are assumed to be non-biased (in intensity and distribution), a discrepancy between modelled and observed deposition footprints may arise as a result of the application of a single set of scavenging coefficients (which do not vary as a function of particle diameter) in the parameterization of wet deposition.

Field data shows that particle removal processes strongly depend on particle size distribution through non-linear processes. Impaction/below cloud scavenging is much more efficient for particles with diameters below $0.3 \mu \mathrm{m}$ or above $1-2 \mu \mathrm{m}$ than for particles in the range $0.3-1 \mu \mathrm{m}$ [17]. Since ${ }^{137} \mathrm{Cs}$ was observed attached to particles with diameters spanning the $0.3-1 \mu \mathrm{m}$ size range $[10,18]$, we hypothesise that including particle-size dependent scavenging coefficients will result in better agreement with the observations. 
Other studies, $[19,20]$ have reported the presence of spherical glassy microparticles containing caesium, uranium and other elements characteristic of nuclear fuel and reactor materials, approximately $170 \mathrm{~km}$ from the damaged Fukushima reactor. These Cs-rich microparticles are sparingly soluble in water and have been identified as dominant Cs carriers during the initial Cs fallout in Tokyo, Japan. Therefore, we also represent insoluble particles in the simulations.

In this paper we utilize the co-location of global measurements of two radionuclides released from FDNPP, radioxenon $\left({ }^{133} \mathrm{Xe}\right)$ and caesium $\left({ }^{137} \mathrm{Cs}\right)$, to isolate errors due to the representation of particle size and solubility, in the process of modelling wet deposition in NAME. We test the impact of a particle-size dependent wet deposition parameterisation and examine the possibility that some of the ${ }^{137} \mathrm{Cs}$ was transported on non-soluble particles. This study helps to better understand the physical and chemical form of the material released from FDNPP. The results can be applied to improve atmospheric dispersion modelling over short ranges, where the potential for health impacts is increased (relative to long-ranges, as considered here), for future accidents.

\section{CTBTO measurements}

The Comprehensive Nuclear-Test-Ban Treaty Organisation (CTBTO) network comprised 1 certified stations worldwide in 2011 equipped with particle detection systems of which 25 currently have noble gas detection capability [21]. During March and April 2011 co-located measurements of ${ }^{133} \mathrm{Xe}$ and ${ }^{137} \mathrm{Cs}$ were taken at 11 stations in the Northern Hemisphere at the locations shown in figure 1. 12 and 24-hourly averaged activity concentrations in air of ${ }^{133} \mathrm{Xe}$ and ${ }^{137} \mathrm{Cs}$ are used to evaluate the NAME simulations.

\section{NAME dispersion simulations}

The Lagrangian particle atmospheric dispersion model NAME is used to simulate the dispersion and deposition of ${ }^{133} \mathrm{Xe}$ and ${ }^{137} \mathrm{Cs}$. In this study NAME is driven using 3D meteorological analysis data from the global version of the Met Office's Unified model [22] with 3 hourly temporal resolution (unless otherwise stated) and approximately $25 \mathrm{~km}$ horizontal resolution. Particles are released into the model atmosphere at the location of FDNPP and are transported by the $3 \mathrm{D}$ winds. The effect of small-scale turbulent motions are represented using stochastic perturbations to the particle trajectories. Physical removal processes such as sedimentation, dry and wet deposition are also parameterised in NAME. Wet deposition is the process of removal by precipitation in the atmosphere. Two main processes are involved: washout, where material is removed by falling precipitation, and rainout, where material (acting as cloud condensation nuclei) is absorbed directly onto cloud droplets. Both of these processes are parameterised in NAME. Activity concentration fields are calculated in NAME by dividing the total activity of particles in a given grid-box by its volume. 12-hourly averaged ${ }^{133} \mathrm{Xe}$ and ${ }^{137} \mathrm{Cs}$ activity concentrations in air are output onto a $1^{\circ} \times 1^{\circ}$ latitude/longitude global grid and averaged from 0-2000 m above ground level. Concentrations are averaged over a deeper than usual depth to account for relatively small vertical spatial errors at the receptor location compared to the distance travelled from the source. Sensitivity tests have been performed using different horizontal and vertical averaging scales. 


\section{1. ${ }^{133}$ Xe Emission Rate}

${ }^{133} \mathrm{Xe}$ is an inert isotope of xenon. It therefore serves as a passive tracer of air mass transport. ${ }^{133} \mathrm{Xe}$ is modelled as a gas with a half-life of 5.25 days, no sedimentation, wet or dry-deposition. Figure 2(a) shows the estimated time evolution of ${ }^{133}$ Xe released from FDNPP between 12 - 19 March 2011 [23]. There were 3 main releases occurring on 12, 13 and 15 March 2011 with smaller releases in between.

\section{2. ${ }^{137}$ Cs Emission Rate and particle size distribution}

${ }^{137} \mathrm{Cs}$ is an isotope of caesium. This radionuclide has a relatively long half-life of about 30 years. Given the long time-scale for radioactive decay compared to the timescales for transport, emission rate variability, dry and wet deposition, errors in our simulations of ${ }^{137} \mathrm{Cs}$ arising as a result of uncertainties associated with radioactive decay will be insignificant. ${ }^{137} \mathrm{Cs}$ is modelled as a particle with a radioactive decay half-life of 5.25 days. The density of the particles that ${ }^{137} \mathrm{Cs}$ attaches to is assumed to be $335 \mathrm{~kg} \mathrm{~m}^{-3}$. However, given their small size, sedimentation rates are negligible and the results are insensitive to this assumed value. A dry deposition velocity of $1 \times 10^{-3} \mathrm{~m} \mathrm{~s}^{-1}$ was assumed when modelling ${ }^{137} \mathrm{Cs}$, consistent with the values used in numerical simulations by Public Health England, the Japanese Atomic Energy Agency and the Institute for Radiological Protection and Nuclear Safety [24, 25]. Figure 2(b) shows the estimated time evolution of ${ }^{137} \mathrm{Cs}$ released from FDNPP [26]. The largest release occured on 12 March 2011 but significant releases continued until 21 March 2011.

In the context of radiation protection, activity median aerodynamic diameter (AMAD) is defined such that $50 \%$ of the radioactivity is associated with particles smaller than the AMAD and $50 \%$ of the radioactivity is associated with particles larger than the AMAD. [27] provide a summary of measured AMADs of radioactive particles from FDNPP. Based on measurements taken in Japan the ${ }^{137} \mathrm{Cs}$ AMAD was in the range 0.5-11.5 $\mu \mathrm{m}$ depending on the distance from the FDNPP and measurement period [28, 10, 19, 29, 18] and in Europe the measured AMAD was between $0.25-0.7 \mu \mathrm{m}[30,31]$. The size distribution of the particles has been found to be bimodal in Japan [28] with peaks at $0.5 \mu \mathrm{m}$ and $6 \mu \mathrm{m}$. However, the $6 \mu \mathrm{m}$ peak is thought to stem from the re-suspension of deposited radioactivity on soil particles. Whilst initial assumptions were that ${ }^{137} \mathrm{Cs}$ attached predominantly to soluble particles, more recently spherical hydrophobic microparticles with a high ${ }^{137} \mathrm{Cs}$ concentration have been observed in the deposits within the vicinity of the FDNPP [32, 20, 33]. For example, [34] showed that low-solubility Caesium rich microparticles (CsMPs) $0.58-2.0 \mu \mathrm{m}$ in diameter constituted $80 \%$ to $89 \%$ of the total Cs radioactivity in the Tokyo area.

In this paper the impact of different particle size distributions (psd) including both soluble and insoluble particles is investigated. Binned psd 1 (table 1) is based on the measurements of [18]. Given that the samples in their study were obtained 4 months after the major release of radioactivity, airborne radioactivity was likely to represent re-suspended deposited radioactivity, rather than direct transport from the source. Thus a second simulation (Binned psd 2, table 1) was performed in which the Coarse $(1-10 \mu \mathrm{m})$ and Giant $(10-100 \mu \mathrm{m})$ mode particles are moved to the Accumulation mode to represent more closely the European size distribution measurements of $[30,31]$. Finally, to test the potential importance of representing insoluble CsMPs in our intercontinental simulations of dispersion and deposition a third simulation was performed in which insoluble particles are represented (Binned psd 3, table 1).

In summary, 4 experiments were performed. 


\begin{tabular}{|c|c|c|c|c|c|c|}
\hline $\begin{array}{c}\text { Particle } \\
\text { bin }\end{array}$ & Particle & Bulk & \multicolumn{4}{|c|}{ Binned } \\
\hline & diameter $(\mu \mathrm{m})$ & & psd 1 & psd 2 & \multicolumn{2}{|c|}{ psd 3 } \\
\hline Aitken & & $\mathrm{S}$ & $\mathrm{S}$ & $\mathrm{S}$ & $\mathrm{S}$ & $\mathrm{I}$ \\
\hline Accumulation & $0.01-0.1$ & - & 0.05 & 0.05 & 0.01 & 0.04 \\
Coarse & $0.1-1.0$ & 1.00 & 0.45 & 0.95 & 0.19 & 0.76 \\
Giant & $1.0-10$ & - & 0.45 & 0.00 & 0.00 & 0.00 \\
\hline
\end{tabular}

Table 1: Fraction of ${ }^{137} \mathrm{Cs}$ activity carried by particles of different diameters used in Bulk and Binned particle size simulations. Activity distribution for soluble (S) and insoluble (I) particles. Bulk particle size diameter is $0.8 \mu \mathrm{m}$.

- Bulk: A particle size of $0.8 \mu \mathrm{m}$ and constant bulk scavenging coefficients are used (as shown in figures 3 and 4). All particles are assumed to be soluble.

- Binned psd 1: Particle size dependent scavenging coefficients are implemented. An equal distribution of activity in the Accumulation $(0.1-1 \mu \mathrm{m}$ diameter) and Coarse $(1.0-10 \mu \mathrm{m}$ diameter) size bins is used. All particles are assumed to be soluble.

- Binned psd 2: As for binned psd 1 experiment but the fraction of the total activity carried by particles in the Coarse and Giant mode bins are set to zero and the remaining activity is added to the Accumulation mode particles. All particles are assumed to be soluble.

- Binned psd 3: As for binned psd 2 experiment but the percentage of the total activity carried by soluble particles is reduced by $80 \%$ and the remaining activity is carried by insoluble particles of the same size.

Note that the results do not change if binned psd 2 and 3 contain small amounts of coarse and giant mode particles since these larger particles are largely removed from the atmosphere by dry and wet-deposition (including sedimentation) before reaching the CTBTO receptor stations. In psd 3 an insoluble fraction of $80 \%$ is used since [34] showed that low-solubility CsMPs accounted for between $80-89 \%$ of the total Cs radioactivity measured. To test sensitivity to this, the insoluble fraction in psd 3 was varied from 70-90\% and the conclusions do not change (not shown).

\subsection{Bulk particle size wet deposition parameterisation (default)}

The default wet deposition parameterisation in NAME is a bulk parameterisation in which the removal of material from the atmosphere due to wet deposition is particle size independent. The removal of material from the atmosphere by wet deposition processes is based on the depletion equation

$$
\frac{d C}{d t}=-\Lambda C
$$

where $\mathrm{C}$ is pollutant concentration, $\mathrm{t}$ is time and $\Lambda$ is a scavenging coefficient. The scavenging coefficient, $\Lambda$, is given by

$$
\Lambda=a r^{b}
$$

where $\mathrm{r}$ is precipitation rate in $\mathrm{mm} \mathrm{h}^{-1}$ and $a$ and $b$ are scavenging parameters that vary for different types of precipitation (e.g. rain or snow) and the process being represented (e.g. washout or rainout) [35]. The values for $a$ and $b$ are based on observations and detailed cloud modelling [36] and are shown in figures 3 and 4 . 


\subsection{Particle size dependent wet deposition parameterisation}

The efficiency of below-cloud and in-cloud wet scavenging processes is known to depend on the particle size and the particle properties [17, 37]. Effectual cloud condensation nuclei are submicron in size $(\sim 0.08-1.0 \mu \mathrm{m})$ and hygroscopic (water absorbing). Below-cloud scavenging is efficient for very small particles $(<\sim 0.01 \mu \mathrm{m})$, due to their Brownian motion, and for Coarse particles (of the order of a few microns), which are readily collected by impaction due to their inertia. Below-cloud scavenging is much less efficient for particles in the intermediate size range, which tend to be swept along streamlines and around falling precipitation elements, thereby escaping capture. Improvements over a bulk wet deposition parameterisation are possible if variations in the scavenging coefficient with particle size are included.

A particle size dependent wet deposition parameterisation has recently been developed for NAME [37] based on the work of [38, 39] and [40]. Figure 3 shows the variation with particle size of the below-cloud scavenging parameters ( $a$ and $b$ ), together with, for comparison, the default bulk scavenging parameters. In cloud (figure 4), the particle size dependent wet deposition parameterisation uses bin-defined scavenging coefficients $\left(\Lambda_{i}\right)$ for different particle size diameter $(d)$ bins (nucleation: $d \leq 0.01 \mu \mathrm{m}$, Aitken: $0.01<d \leq 0.1 \mu \mathrm{m}$, Accummulation: $0.1<d \leq 1.0 \mu \mathrm{m}$ and Coarse: $d>1.0 \mu \mathrm{m}$ ). The bin-defined scavenging coefficient takes the form

$$
\Lambda_{i}=a_{i} r^{b}=\tilde{a} R_{i} r^{b}
$$

where $\tilde{a}=5.2 \times 10^{4} \mathrm{~s}^{-1}$ and $b=0.79$ are constants which do not vary with particle size. $R_{i}$ is the in-cloud scavenging ratio for particle mode $i$ and is defined as the fraction of the in-cloud particles in mode $i$ that are embedded within the cloud liquid water / cloud ice [40]. The incloud scavenging ratio depends on the phase of the cloud and whether the particle is hygroscopic (soluble) or hydrophobic (insoluble). Figure 4 shows the variation of the particle size dependent in-cloud scavenging parameter $a_{i}$ with particle size in liquid, mixed and ice phase clouds, for soluble and insoluble particles. The bulk in-cloud scavenging parameters (which do not vary with particle size or solubility) are also shown for comparison.

\section{Statistical evaluation}

There is a wide range in the magnitude of observed and modelled concentrations, due to the use of data with distances from 1000 to $10,000 \mathrm{~km}$ from FDNPP. As both the ${ }^{133} \mathrm{Xe}$ and ${ }^{137} \mathrm{Cs}$ activity concentrations at different receptor locations can vary by up to 2 orders of magnitude, they are $\log$ transformed before the statistics are calculated. Background ${ }^{133} \mathrm{Xe}$ and ${ }^{137} \mathrm{Cs}$ concentrations at each measurement site are estimated by averaging the lowest 4 concentrations measured at each site during the period $11 / 3 / 2011$ to $11 / 5 / 2011$. Background concentrations are expected to be present due to nuclear testing fall-out and medical isotope production facilities. The background concentration is added to the NAME estimated concentration before the statistics are calculated. All statistics are calculated for times at which both the observations and NAME simulations are non-zero. Three statistics are used to compare the NAME simulations with the CTBTO observations:

1. Root Mean Square Logarithmic Error (RMSLE)

The RMSLE gives a measure of the difference between the activity concentrations predicted by NAME and the observed activity concentrations. The advantage of RMSLE is 
that it doesn't penalize large differences in the modelled and the observed values when both modelled and observed values are large numbers.

$$
\log _{10}(R M S L E)=\sqrt{\frac{1}{N} \sum_{t=1}^{N}\left[\log _{10}\left(x_{t}\right)-\log _{10}\left(y_{t}\right)\right]^{2}}
$$

where $x_{t}$ is the observed concentration and $y_{t}$ is the simulated concentration at time $t$. This is calculated using $\mathrm{N}$ concentration values, when both $x_{t}$ and $y_{t}$ are non-zero. Subtracting two log transformed values is equivalent to the $\log$ of the ratio of the values. Therefore, when RMSLE equals 10, this signifies that the predicted value is on average within a factor of 10 of the observed concentration.

2. Geometric Mean Bias (GMB)

The GMB gives a measure of model overestimation or underestimation. This logarithmic form of bias is appropriate in this study because it ensures that underpredictions and overpredictions receive equal weight.

$$
\log _{10}(G M B)=\frac{1}{N} \sum_{t=1}^{N} \log _{10}\left(x_{t}\right)-\frac{1}{N} \sum_{t=1}^{N} \log _{10}\left(y_{t}\right)
$$

As for RMSLE, to compare the GMB at different receptor locations, the ratio of observed to NAME simulated activity concentrations are compared. Thus when GMB equals 0.5 , this signifies that NAME underestimates the observed geometric mean by a factor of 2 . When GMB equals 2, this signifies that NAME overestimates the observed geometric mean by a factor of 2 .

3. Correlation

The Pearson correlation coefficient is used to measure the linear relationship between the observed $(x)$ and simulated $(y)$ concentrations. It varies between -1 and +1 with 0 implying no correlation. Positive correlations imply $x$ increases as $y$ increases and vice versa. To determine whether the correlation between variables is significant, the p-value to the significance level is compared. A p-value $<0.01$ is used to indicate that the correlation is significant at the $99 \%$ confidence level.

\section{Wet deposition error identification}

The methodology used to identify errors due to the representation of wet deposition in this NAME modelling study involves 3 steps as follows:

Step 1: Identify receptor locations at which the time series of observed and simulated ${ }^{133} \mathrm{Xe}$ are: significantly correlated $(p<0.01)$; RMSLE is small ( $\leqslant$ factor of 10$)$ and GMB is small ( $\leqslant$ factor of 5). At these receptor locations, errors in the simulation of ${ }^{137} \mathrm{Cs}$ activity concentrations in air that are due to transport can be assumed to be small since ${ }^{133} \mathrm{Xe}$ is passive and undergoes no sedimentation or dry-deposition.

Step 2: At the receptor locations identified in step 1, identify receptor locations at which the simulated time series of ${ }^{133} \mathrm{Xe}$ and ${ }^{137} \mathrm{Cs}$ (without wet deposition represented) are significantly correlated $(p<0.01)$. There is almost no correlation in the source emissions of ${ }^{133} \mathrm{Xe}$ and ${ }^{137} \mathrm{Cs}$ (figure 2(a) and (b)), and ${ }^{133} \mathrm{Xe}$ is not subject to sedimentation or dry deposition. Therefore, any 
significant correlations in the activity concentrations at the receptor locations mean that errors in temporal fluctuations of the source, sedimentation or dry deposition rates of ${ }^{137} \mathrm{Cs}$ do not dominate errors in the simulation of ${ }^{137} \mathrm{Cs}$ activity (systematic errors in the magnitude of the source can still contribute to the RMSLE and GMB).

Step 3: At the receptor locations identified in step 2, compare the time series of observed and simulated ${ }^{137} \mathrm{Cs}$ using different wet deposition parameterisations including a dependency on particle size and solubility assumptions. In this comparison errors in the simulation of ${ }^{137} \mathrm{Cs}$ activity concentrations in air that are not due to evolution of the emission magnitude or transport have been isolated and the accuracy of different representations of wet deposition can be compared.

\section{Results: Transport of ${ }^{133} \mathrm{Xe}$}

Figure 5 shows the evolution of predicted ${ }^{133} \mathrm{Xe}$ activity concentrations in air, between 0 and $2000 \mathrm{~m}$ above ground level, released from FDNPP. Approximately 4 days after the start of the release (figure 5(a)) the ${ }^{133} \mathrm{Xe}$ plume has been transported up to $2000 \mathrm{~km}$ east of FDNPP across the north Pacific Ocean. Approximately 7 days after the start of the release (figure 5(b)) the ${ }^{133} \mathrm{Xe}$ plume has now reached the east coast of the US (approximately $5000 \mathrm{~km}$ from FDNPP). The plume now covers large parts of the north Pacific Ocean with evidence of cyclonic transport by extratropical cyclones in both the west and east Pacific. Approximately 10 days after the start of the release (figure 5(c)) a filament of the ${ }^{133} \mathrm{Xe}$ plume has reached Europe $(>10000 \mathrm{~km}$ from FDNPP). The ${ }^{133} \mathrm{Xe}$ is very widely dispersed by this time, covering much of the north Pacific and the north American continent.

In order to evaluate the accuracy of the representation of the meteorological processes responsible for this inter-continental transport the time evolution of NAME and observed ${ }^{133} \mathrm{Xe}$ activity concentrations in air at CTBTO sites in the northern hemisphere (step 1) are compared. To account for the accumulated effect of small errors in the meteorological fields, $0-2000 \mathrm{~m}^{133} \mathrm{Xe}$ concentrations from the NAME simulations averaged over $1^{\circ} \times 1^{\circ}$ lat/lon areas (approximately $100 \mathrm{~km}$ by $100 \mathrm{~km}$ ) are compared with the surface level concentrations measured at the CTBTO locations, noting that care should be taken when comparing a point measurement (observation) to an area averaged model simulation as the point measurement may not be representative of the larger area. Material is assumed to be well-mixed in the boundary layer at the distances investigated in this study. As ${ }^{133} \mathrm{Xe}$ is, to first order, an inert gas (non-reactive and non-depositing) it provides an excellent tracer to perform this evaluation.

Figure 6 shows the evolution of observed (CTBTO measurements) and NAME simulated ${ }^{133} \mathrm{Xe}$ activity concentrations in air (with background concentrations included) at selected CTBTO locations. Figure 6(a) shows the ${ }^{133} \mathrm{Xe}$ concentrations at Oahu in the Pacific. This was one of the first stations to observe elevated concentrations of ${ }^{133} \mathrm{Xe}$. The NAME simulated ${ }^{133} \mathrm{Xe}$ concentrations are on average within a factor of 3 of the CTBTO ${ }^{133} \mathrm{Xe}$ concentrations at Oahu. They have a correlation of 0.95 with the observations, which is significant at the $99 \%$ confidence level, and underestimate the geometric mean by a factor of 2 (table 2). Similar comparison of the NAME simulated ${ }^{133}$ Xe concentrations at stations further away (figures 6(b)-(f)) show that as the distance from FDNPP increases the RMSLE generally increases from within a factor of 2-3 in the Pacific, a factor of 4-6 in the US and a factor of 4-8 in Europe (table 2).

At one receptor site, Ussuriysk, the RMSLE is greater than a factor of 10 indicating poor agreement with the observations. This is due to a large overestimation of ${ }^{133} \mathrm{Xe}$ between 23 27 March 2011 (figure 6(f)). Although this receptor is closest to Fukushima it is also upwind 


\begin{tabular}{|c|c|c|c|c|c|c|c|c|c|c|c|}
\hline & 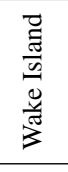 & 胥 & $\begin{array}{l}\stackrel{0}{\vec{J}} \\
\frac{0}{3} \\
\frac{0}{0}\end{array}$ & 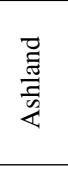 & 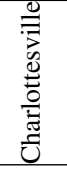 & $\begin{array}{l}\stackrel{n}{\Xi} \\
\stackrel{0}{0} \\
\stackrel{\infty}{\infty}\end{array}$ & 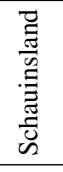 & 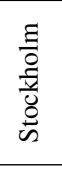 & 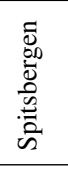 & 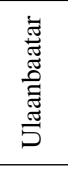 & 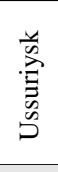 \\
\hline Correlation & 0.95 & 0.95 & 0.77 & 0.90 & 0.80 & 0.84 & 0.94 & 0.84 & 0.94 & 0.91 & 0.18 \\
\hline RMSLE & 2 & 3 & 6 & 4 & 4 & 4 & 4 & 5 & 8 & 4 & 13 \\
\hline GMB & $1 / 2$ & $1 / 2$ & $1 / 3$ & $1 / 2$ & $1 / 2$ & $1 / 2$ & $1 / 3$ & $1 / 3$ & $1 / 7$ & $1 / 3$ & 1 \\
\hline
\end{tabular}

Table 2: Statistics are calculated for $\log _{10}\left({ }^{133} \mathrm{Xe}\right)$. Grey shading indicate receptors at which the correlation is not significant at the $99 \%$ confidence level, RMSLE is $>10$, GMB $>5$ or GMB $<1 / 5$.

and thus in the simulations the radioactive material circumnavigates the Earth before it reaches Ussurisk. In addition, the correlation between the observed and simulated ${ }^{133} \mathrm{Xe}$ activity concentrations in air is not significant at the 99th percentile confidence level at Ussuriysk (table 2). Also, at Spitsbergen the GMB is less than a factor of $1 / 5$ indicating poor agreement with the observations (although the correlation is high). Therefore Ussuriysk and Spitsbergen are removed from all further analysis as transport errors cannot be ruled out.

At all other stations the correlation between the NAME ${ }^{133} \mathrm{Xe}$ concentration and the observed ${ }^{133} \mathrm{Xe}$ concentrations remains significant at the $99 \%$ confidence level showing that the simulations of ${ }^{133} \mathrm{Xe}$ are skillful even at inter-continental distances from FDNPP. Thus the NAME simulations contain a good representation of the meteorological processes responsible for the inter-continental transport of ${ }^{133} \mathrm{Xe}$ to these receptor locations. It is not the purpose of this paper to examine the cause of the transport errors to Ussuriysk and Spitsbergen.

\section{Results: Transport and deposition of ${ }^{137} \mathrm{Cs}$}

In this section the ability to correctly simulate the transport and deposition of ${ }^{137} \mathrm{Cs}$ using NAME is evaluated.

\subsection{Emission rate, sedimentation rate and dry deposition rate}

To evaluate the potential impact of errors in factors other than wet-deposition, NAME simulations in which the wet deposition of ${ }^{137} \mathrm{Cs}$ is not represented are performed. Comparing the time series of simulated ${ }^{137} \mathrm{Cs}$ and simulated ${ }^{133} \mathrm{Xe}$ activity concentrations in air at the CTBTO locations therefore allows us to assess the importance of the emission rate fluctuations, sedimentation and dry deposition rates (step 2). Table 3 shows the correlation between NAME simulated ${ }^{137} \mathrm{Cs}$ (no wet deposition) and simulated ${ }^{133} \mathrm{Xe}$ at the CTBTO locations identified in step 1. The correlations between NAME simulated ${ }^{137} \mathrm{Cs}$ (no wet deposition) and simulated ${ }^{133} \mathrm{Xe}$ are significant at the $99 \%$ level at all stations. Thus we conclude that the simulated concentrations are not very sensitive to the emission time profile characteristics, the sedimentation or dry deposition rates. Therefore, for the following analysis it is assumed that any discrepancies between the NAME simulated ${ }^{137} \mathrm{Cs}$ concentrations and observed ${ }^{137} \mathrm{Cs}$ concentrations are not due to errors in the meteorological transport to these receptor locations or to errors in the emission rate fluctuations, sedimentation or dry deposition rates. This does not however, rule out systematic bias in the emission rate magnitude.

We also compare observed concentrations of ${ }^{137} \mathrm{Cs}$ with NAME simulations of $137 \mathrm{Cs}$ in which the wet deposition is not represented. Table 4 shows that, for all stations, NAME overestimates 


\begin{tabular}{|c|c|c|c|c|c|c|c|c|c|}
\hline & 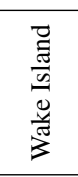 & 疋 & $\begin{array}{l}\frac{0}{2} \\
\frac{\bar{\theta}}{3} \\
\frac{\bar{D}}{2}\end{array}$ & $\frac{\vec{J}}{\frac{\vec{J}}{\bar{n}}}$ & 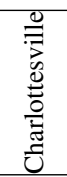 & $\frac{\mathscr{E}}{\stackrel{0}{0}}$ & 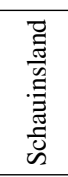 & $\begin{array}{l}\frac{\Xi}{0} \\
\frac{\Xi}{\frac{1}{0}} \\
\frac{0}{\omega} \\
\frac{D}{n}\end{array}$ & 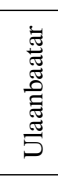 \\
\hline Correlation & 0.53 & 0.45 & 0.72 & 0.69 & 0.54 & 0.38 & 0.61 & 0.41 & 0.61 \\
\hline
\end{tabular}

Table 3: Correlation between NAME $\log _{10}\left({ }^{137} \mathrm{Cs}\right)$ subject to dry-deposition only, and NAME $\log _{10}\left({ }^{133} \mathrm{Xe}\right)$. The correlations are significant at the $99 \%$ confidence level.

${ }^{137} \mathrm{Cs}$ activity by at least two orders of magnitude when wet deposition is not represented. Since there is no removal of ${ }^{137} \mathrm{Cs}$ by wet-deposition too much material remains in the atmosphere. Furthermore, when wet deposition is not represented the simulations are only significantly correlated at 2 out of 9 receptor stations.

\subsection{Bulk wet deposition parameterisation}

The NAME simulations of ${ }^{137} \mathrm{Cs}$ analysed in section 7.1 did not contain a representation of wet deposition. In this section simulations in which both dry and wet deposition processes are included are performed. The representation of wet deposition of ${ }^{137} \mathrm{Cs}$ is described in section 3.3. Figure 7 shows the evolution of observed CTBTO measurements and NAME simulated ${ }^{137} \mathrm{Cs}$ activity concentrations in air for the selected receptor locations where it is assumed that errors in the transport, sedimentation or dry deposition rates or emission rate fluctuations do not contribute significantly to discrepancies. For NAME simulations using the bulk wet deposition parameterisation, the highest ${ }^{137} \mathrm{Cs}$ activity concentrations in air occur at Oahu $\left(>10^{3} \mu \mathrm{Bq} \mathrm{m}^{-3}\right)$. There is also a high correlation, a small RMSLE and a GMB that is closer to 1 at this location (table 4). Particles reaching Oahu experience, on average, the shortest travel time from Fukushima (8.9 days) compared to the other receptor locations and thus the potential for small errors in the wind fields to accumulate along the particle trajectories is smaller than for the other measurement locations.

For the NAME simulations using the bulk wet deposition parameterisation ${ }^{137} \mathrm{Cs}$ concentrations are on average within a factor of 8 of the CTBTO ${ }^{137} \mathrm{Cs}$ concentrations at Ashland (Figure 7(b)). They have a correlation of 0.62 with the observations, which is significant at the $99 \%$ confidence level, and they underestimate the geometric mean by a factor of 7 . Similar comparisons of NAME simulated ${ }^{137} \mathrm{Cs}$ concentrations at stations further away (figures 7(c)-(f)) show that as the distance from FDNPP increases the RMSLE is high, typically greater than a factor of 20 at all stations, the correlation is not significant at 5 of the stations (55\%) and there remains a large underestimation of the geometric mean (up to a factor of 38). Thus too much activity is removed from the particles via wet deposition using the bulk wet deposition parameterisation (en-route to the CTBTO stations considered here). Sensitivity to the spatial and vertical averaging scales has been performed and the results do not depend on these choices (see Appendix table A.5).

The large underestimation in simulated ${ }^{137} \mathrm{Cs}$ could be due to errors in the activity removal rates when the particles encounter precipitation. This could be caused by a systematic overestimation in the numerical weather prediction (NWP) precipitation rates. For example, the wetdeposition scheme assumes that precipitating clouds are stationary between NWP meteorology input times (in this case 3 hours), whereas the particle positions evolve every model timestep (in this case 15 minutes). However, in the atmosphere it is likely that the meteorological cloud and 
the radioactive cloud would move with a similar velocity (known as Lagrangian persistence). This lack of Lagrangian persistence could result in the application of wet-deposition to a greater number of particles than it should or for a longer period of time. Therefore, simulations in which 1-hourly, 3-hourly and 6-hourly meteorological input was used were performed. There was no systematic improvement in the correlation statistics when higher temporal frequency wind and precipitation data was used. There was however, an order of magnitude reduction in both the RMSLE and GMB when the temporal frequency was increased from 6-hourly to 3-hourly, but no significant improvement when hourly meteorological input data was used (not shown). Since 3-hourly NWP is used in the simulations in section 7.2 this suggests that the lack of Lagrangian persistence is not the dominant reason for low-skill in the ${ }^{137} \mathrm{Cs}$ simulations.

The large underestimation in simulated ${ }^{137} \mathrm{Cs}$ could be due to an overestimation of the scavenging coefficients used in the bulk parameterisation. In particular, evidence in the literature suggests that the wet-deposition of particles depends on the size of the particles [17]. The potential that the scavenging coefficients used in NAME are too large for the range of ${ }^{137} \mathrm{Cs}$ particle sizes modelled here is investigated.

\subsection{Particle size dependent wet deposition parametrisation}

The NAME simulations of ${ }^{137} \mathrm{Cs}$ analysed in section $7.2 \mathrm{did}$ not represent the dependence of wet deposition on particle size. In this section NAME simulations using a particle size dependent wet deposition parameterisation (described in section 3.4) are performed.

\subsubsection{Soluble particles (psd 1)}

Figure 7 and table 4 show a comparison of the ${ }^{137} \mathrm{Cs}$ concentrations simulated using the particle size dependent wet deposition parameterisation. When using the particle size distribution representative of that measured by [18] (psd 1, table 1) there is an increase in the correlation statistics at all of the sites. The improvement in correlation could be due to different sedimentation rates from the different particle size distribution. However simulations using psd 1 and the bulk wet deposition parameterisation scheme perform in a similar manner to simulations using the bulk psd and the bulk wet deposition parameterisation scheme (not shown). Therefore, including different sedimentation rates from the different particle size distribution does not improve the simulations. Thus it is likely that improvements using psd 1 and the size dependent wet deposition scheme are not due to sedimentation. The RMSLE decreases at all sites, by an average of a factor of 7 and the GMB decreases at all sites by on average a factor of 5 when compared to the bulk psd simulations. Figure 3(a) shows that for $0.01-3 \mu$ m diameter particles the below-cloud scavenging parameter $(a)$ is smaller than that used in the bulk scheme and for $3-100 \mu \mathrm{m}$ particles $(a)$ is larger than that used in the bulk scheme. Figure 4(a) shows that for $0.01-0.1 \mu \mathrm{m}$ diameter particles the in-cloud scavenging parameter $(a)$ is smaller than that used in the bulk scheme and for $0.1-10 \mu \mathrm{m}$ particles $(a)$ is larger than that used in the bulk scheme. Thus, there is both enhanced and supressed wet deposition depending on the particle size. The RMSLE and GMB both reduce for psd 1 suggesting that the combined effect is a reduction in wet deposition overall, but there remains a large underestimation of ${ }^{137} \mathrm{Cs}$ concentrations at the distal sites.

\subsubsection{Soluble submicron particles ( $p s d 2)$}

The particle size distribution (psd 1) contains a peak in the Accumulation mode (approximately $0.5 \mu \mathrm{m}$ ) and a second peak in the Coarse mode (approximately $6 \mu \mathrm{m}$ ). However, the $6 \mu \mathrm{m}$ peak is 


\begin{tabular}{|c|c|c|c|c|c|c|c|c|c|}
\hline & 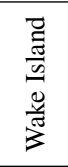 & 胥 & 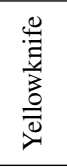 & $\frac{\vec{Z}}{\frac{\vec{J}}{\mathbb{Z}}}$ & 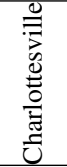 & $\begin{array}{l}\stackrel{\mathscr{E}}{0} \\
\stackrel{0}{0} \\
\stackrel{n}{n}\end{array}$ & 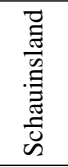 & 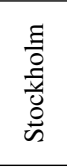 & 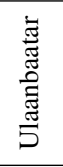 \\
\hline \multicolumn{10}{|l|}{ Correlation } \\
\hline Bulk (no wet dep) & 0.37 & 0.55 & 0.63 & 0.00 & 0.21 & 0.67 & 0.26 & 0.40 & 0.40 \\
\hline Bulk & 0.52 & 0.74 & 0.08 & 0.62 & 0.34 & 0.25 & 0.32 & 0.49 & 0.31 \\
\hline psd 1 & 0.82 & 0.82 & 0.36 & 0.69 & 0.52 & 0.48 & 0.75 & 0.58 & 0.53 \\
\hline psd 2 & 0.82 & 0.82 & 0.37 & 0.68 & 0.52 & 0.48 & 0.75 & 0.59 & 0.55 \\
\hline psd 3 & 0.87 & 0.85 & 0.48 & 0.71 & 0.59 & 0.46 & 0.71 & 0.58 & 0.76 \\
\hline \multicolumn{10}{|l|}{ RMSLE } \\
\hline Bulk (no wet dep) & 441 & 345 & 50 & 282 & 210 & 159 & 199 & 154 & 223 \\
\hline Bulk & 14 & 8 & 44 & 8 & 18 & 42 & 8 & 20 & 16 \\
\hline psd 1 & 3 & 5 & 30 & 6 & 11 & 23 & 7 & 14 & 12 \\
\hline psd 2 & 4 & 5 & 30 & 5 & 11 & 23 & 7 & 14 & 12 \\
\hline psd 3 & 4 & 5 & 10 & 4 & 5 & 9 & 4 & 6 & 4 \\
\hline \multicolumn{10}{|l|}{ GMB } \\
\hline Bulk (no wet dep) & 319 & 252 & 45 & 192 & 166 & 129 & 170 & 133 & 187 \\
\hline Bulk & $1 / 7$ & $1 / 4$ & $1 / 38$ & $1 / 7$ & $1 / 13$ & $1 / 26$ & $1 / 7$ & $1 / 16$ & $1 / 11$ \\
\hline psd 1 & $1 / 2$ & $1 / 2$ & $1 / 26$ & $1 / 5$ & $1 / 8$ & $1 / 14$ & $1 / 6$ & $1 / 11$ & $1 / 8$ \\
\hline psd 2 & 1 & $1 / 2$ & $1 / 26$ & $1 / 5$ & $1 / 8$ & $1 / 14$ & $1 / 6$ & $1 / 11$ & $1 / 8$ \\
\hline psd 3 & 2 & 1 & $1 / 7$ & $1 / 2$ & $1 / 2$ & $1 / 3$ & $1 / 3$ & $1 / 4$ & $1 / 3$ \\
\hline
\end{tabular}

Table 4: Wet deposition evaluation statistics for the simulations including particle size distributions described in section 3.2 and Table 1. The bulk (no wet dep) simulation contains no representation of wet deposition. Statistics calculated for $\log _{10}\left({ }^{137} \mathrm{Cs}\right)$. Grey shading indicate receptors at which the correlation is not significant at the $99 \%$ confidence level, RMSLE is $>10, \mathrm{GMB}>5$ or GMB $<1 / 5$. 
thought to stem from the re-suspension of deposited radioactivity on soil particles. Therefore psd 2 represents a particle size distribution in which this $6 \mu \mathrm{m}$ peak is removed. To conserve the total activity, the removed activity is redistributed onto the Accumulation mode particles. Figure 7 and table 4 show the result of this simulation. It can be seen that there is very little difference between the simulations using psd 1 and psd 2 (the blue and cyan lines overlap and statistics are almost identical). Figures 3 and 4 show that both the in-cloud and below-cloud scavenging will reduce when activity is redistributed onto the Accumulation mode particles. As a result the Accumulation mode activity in North America, Europe and Asia more than doubles, but since the total activity is dominated by the Aitken mode particles, the total activity over the entire period only increases by a relatively small amount $(2-17 \%)$. Therefore, in NAME, increasing the fraction of activity carried by soluble submicron particles does not improve the correlations or decrease the underestimation of observed activity concentrations.

\subsubsection{Insoluble submicron particles (psd 3)}

There is evidence that a high fraction of insoluble particles may have been released into the atmosphere during the FDNPP releases [41]. The new wet-deposition scheme implemented in NAME allows the possibility to model particles as either soluble or insoluble. The particle size dependent in-cloud scavenging coefficients for insoluble particles are lower than for soluble particles (figure 4). Psd 3 (table 1) simulations were performed to account for a significant contribution in the fraction of activity carried by insoluble particles. Psd 3 represents $80 \%$ of the submicron particles as insoluble particles. This is consistent with the results of [34] who showed that low-solubility CsMPs constituted $80 \%$ to $89 \%$ of the total Cs radioactivity in the Tokyo area. Compared to the psd 2 experiments, the correlations increased at 6 of the sites $(67 \%)$ and the RMSLE decreased by a factor of 7. NAME is able to simulate the observed ${ }^{137} \mathrm{Cs}$ activity concentrations in air to within a factor of 10 (RMSLE $<10)$ at all sites and the bias has reduced to within a factor of 7 . This suggests that inclusion of insoluble submicron particles in NAME is necessary to capture the evolution and magnitude of ${ }^{137} \mathrm{Cs}$ over inter-continental dispersion scales.

\section{Conclusions}

In this paper simulations of ${ }^{133} \mathrm{Xe}$ and ${ }^{137} \mathrm{Cs}$ using the UK Met Office NAME dispersion model were performed and compared with CTBTO activity concentration in air surface station measurements. For ${ }^{133} \mathrm{Xe}$ the NAME simulated activity concentrations are significantly correlated with the CTBTO ${ }^{133} \mathrm{Xe}$ concentrations at 10 out of the 11 northern hemisphere receptor locations studied. However, NAME underestimates the mean ${ }^{133} \mathrm{Xe}$ concentrations at all of the receptor locations by an equal amount suggesting that the emission source used for ${ }^{133} \mathrm{Xe}$ may be underestimated. The total amount of ${ }^{133} \mathrm{Xe}$ released in these simulations is $7.4 \times 10^{18} \mathrm{~Bq}$. This is at the lower end of International Atomic Energy Agency's (IAEA) estimated range of releases of ${ }^{133} \mathrm{Xe}, 6-12 \times 10^{18} \mathrm{~Bq}[42]$

For ${ }^{137} \mathrm{Cs}$ it is shown that improvements to the wet deposition scheme that include the representation of both particle size dependent scavenging coefficients and solublility dependent scavenging coefficients significantly improves the accuracy of NAME simulations. NAME is able to predict ${ }^{137} \mathrm{Cs}$ activity concentrations in air with good accuracy at distances greater than $10,000 \mathrm{~km}$ from FDNPP (within a factor of 10 of observed ${ }^{137} \mathrm{Cs}$ values) if a large fraction of insoluble Accumulation mode particles are represented in the simulations. This result supports 
the recent discovery of Cs-rich microparticles in Japanese soil samples [33, 43] and suggests that these small particles travelled across the Pacific Ocean to the US and further across the North Atlantic Ocean towards Europe. The results suggest that heavier particles and particles subject to higher levels of in-cloud and below-cloud scavenging are efficiently removed from the radioactive cloud by sedimentation, dry and wet-deposition and so do not travel over these inter-continental dispersion scales.

The improved use of particle size dependent wet deposition scheme and consideration of solubility are also applicable to predictions of dispersion and deposition of particles released from other non-nuclear sources such as volcanic eruptions, industrial accidents and forest fires. Future work could consider if similar modelling improvements (in respect of the release following the accident at FDNPP) could better describe the atmospheric dispersion and deposition of isotopes of iodine across the different chemical forms (particulate, elemental vapour and organic).

\section{Acknowledgements}

We would like to acknowledge the work of CTBTO in building up and maintaining its global radioxenon and caesium measurement network. We thank the UK Met Office for providing access to the NAME dispersion model and Peter Clark for producing the high-resolution meteorological data and for helpful discussions on this work. This research did not receive any specific grant from funding agencies in the public, commercial, or not-for-profit sectors.

\section{References}

[1] Y. Amano, The Fukushima Daiichi accident, Tech. Rep. Pub1710, International Atomic Energy Agency (2015). URL https://www-pub. iaea.org/MTCD/Publications/PDF/Pub1710-ReportByTheDG-Web.pdf

[2] L. R. Anspaugh, R. J. Catlin, M. Goldman, The global impact of the Chernobyl reactor accident, Science 242 (4885) (1988) 1513-1519.

[3] P. Thakur, S. Ballard, R. Nelson, An overview of Fukushima radionuclides measured in the northern hemisphere, Science of the total environment 458 (2013) 577-613.

[4] Y. Morino, T. Ohara, M. Watanabe, S. Hayashi, M. Nishizawa, Episode analysis of deposition of radiocesium from the Fukushima Daiichi nuclear power plant accident, Environmental science \& technology 47 (5) (2013) 2314 2322.

[5] T. Nakajima, S. Misawa, Y. Morino, H. Tsuruta, D. Goto, J. Uchida, T. Takemura, T. Ohara, Y. Oura, M. Ebihara, et al., Model depiction of the atmospheric flows of radioactive cesium emitted from the Fukushima Daiichi Nuclear Power Station accident, Progress in Earth and Planetary Science 4 (1) (2017) 2.

[6] S. J. Leadbetter, M. C. Hort, A. R. Jones, H. N. Webster, R. R. Draxler, Sensitivity of the modelled deposition of Caesium-137 from the Fukushima Dai-ichi nuclear power plant to the wet deposition parameterisation in NAME, Journal of environmental radioactivity 139 (2015) 200-211.

[7] A. Stohl, P. Seibert, G. Wotawa, D. Arnold, J. F. Burkhart, S. Eckhardt, C. Tapia, A. Vargas, T. Yasunari, Xenon-133 and caesium-137 releases into the atmosphere from the Fukushima Dai-ichi nuclear power plant: determination of the source term, atmospheric dispersion, and deposition, Atmospheric Chemistry and Physics 12 (5) (2012) 23132343.

[8] T. Chai, R. Draxler, A. Stein, Source term estimation using air concentration measurements and a lagrangian dispersion model - experiments with pseudo and real cesium-137 observations from the Fukushima nuclear accident, Atmospheric Environment 106 (2015) 241-251.

[9] L. Terzi, M. Kalinowski, World-wide seasonal variation of ${ }^{7} \mathrm{Be}$ related to large-scale atmospheric circulation dynamics, Journal of environmental radioactivity 178 (179) (2017). doi:doi.org/10.1016/j.jenvrad.2017.06.031.

[10] N. Kaneyasu, H. Ohashi, F. Suzuki, T. Okuda, F. Ikemori, Sulfate aerosol as a potential transport medium of radiocesium from the Fukushima nuclear accident, Environmental science \& technology 46 (11) (2012) 57205726.

[11] C. Srinivas, R. Venkatesan, R. Baskaran, V. Rajagopal, B. Venkatraman, Regional scale atmospheric dispersion simulation of accidental releases of radionuclides from Fukushima Dai-ichi reactor, Atmospheric environment 61 (2012) 66-84. 
[12] R. Draxler, D. Arnold, M. Chino, S. Galmarini, M. Hort, A. Jones, S. Leadbetter, A. Malo, C. Maurer, G. Rolph, et al., World Meteorological Organization's model simulations of the radionuclide dispersion and deposition from the Fukushima Daiichi nuclear power plant accident, Journal of environmental radioactivity 139 (2015) 172-184.

[13] J. H. Seinfeld, S. N. Pandis, Atmospheric chemistry and physics: from air pollution to climate change, John Wiley \& Sons, 2016.

[14] B. Sportisse, A review of parameterizations for modelling dry deposition and scavenging of radionuclides, Atmospheric Environment 41 (13) (2007) 2683-2698

[15] C. Textor, M. Schulz, S. Guibert, S. Kinne, Y. Balkanski, S. Bauer, T. Berntsen, T. Berglen, O. Boucher, M. Chin, et al., Analysis and quantification of the diversities of aerosol life cycles within Aerocom, Atmospheric Chemistry and Physics 6 (7) (2006) 1777-1813.

[16] M. Kajino, T. T. Sekiyama, A. Mathieu, I. Korsakissok, R. Périllat, D. Quélo, A. Quérel, O. Saunier, K. Adachi, S. Girard, et al., Lessons learned from atmospheric modeling studies after the Fukushima nuclear accident: Ensemble simulations, data assimilation, elemental process modeling, and inverse modeling, Geochemical Journal 52 (2018). doi:doi.org/10.2343/geochemj.2.0503.

[17] S. Greenfield, Rain scavenging of radioactive particulate matter from the atmosphere, Journal of Meteorology 14 (2) (1957) 115-125.

[18] A. Koizumi, K. H. Harada, T. Niisoe, A. Adachi, Y. Fujii, T. Hitomi, H. Kobayashi, Y. Wada, T. Watanabe, H. Ishikawa, Preliminary assessment of ecological exposure of adult residents in Fukushima prefecture to radioactive cesium through ingestion and inhalation, Environmental health and preventive medicine 17 (4) (2012) 292.

[19] K. Adachi, M. Kajino, Y. Zaizen, Y. Igarashi, Emission of spherical cesium-bearing particles from an early stage of the Fukushima nuclear accident, Scientific reports 3 (2013) 2554.

[20] Y. Abe, Y. Iizawa, Y. Terada, K. Adachi, Y. Igarashi, I. Nakai, Detection of uranium and chemical state analysis of individual radioactive microparticles emitted from the Fukushima nuclear accident using multiple synchrotron radiation X-ray analyses, Analytical chemistry 86 (17) (2014) 8521-8525.

[21] CTBTO, https://www.ctbto.org/map, accessed: 2019-08-20 (2019).

[22] M. Cullen, T. Davies, M. Mawson, J. James, S. Coulter, A. Malcolm, An overview of numerical methods for the next generation UK NWP and climate model, Atmosphere-Ocean 35 (sup1) (1997) 425-444.

[23] UNSCEAR, Developments since the 2013 UNSCEAR Report on the levels and effects of radiation exposure due to the nuclear accident following the great east Japan earthquake and tsunami. A 2015 white paper to guide the scientific committee's future programme of work. (2015).

URL https://https://www. unscear.org/unscear/en/publications.html

[24] M.-A. Gonze, P. Renaud, I. Korsakissok, H. Kato, T. G. Hinton, C. Mourlon, M. Simon-Cornu, Assessment of dry and wet atmospheric deposits of radioactive aerosols: application to fukushima radiocaesium fallout, Environmental science \& technology 48 (19) (2014) 11268-11276.

[25] Atmospheric dispersion modelling liaison committee annual report 1998/99, Tech. Rep. NRPB-R322, National Radiological Protection Board (1999).

URL https://admlc.files.wordpress.com/2014/09/r302.pdf

[26] G. Katata, M. Chino, T. Kobayashi, H. Terada, M. Ota, H. Nagai, M. Kajino, R. Draxler, M. Hort, A. Malo, et al., Detailed source term estimation of the atmospheric release for the Fukushima Daiichi Nuclear Power Station accident by coupling simulations of an atmospheric dispersion model with an improved deposition scheme and oceanic dispersion model, Atmospheric Chemistry \& Physics 15 (2) (2015). doi:doi.org/10.5194/acp-15-10292015 .

[27] A. Mathieu, M. Kajino, I. Korsakissok, R. Perillat, D. Quelo, A. Querel, O. Saunier, T. Sekiyama, Y. Igarashi, D. Didier, Fukushima Daiichi derived radionuclides in the atmosphere, transport and deposition in Japan: A review, Applied geochemistry 91 (2018) 122-139.

[28] T. Doi, K. Masumoto, A. Toyoda, A. Tanaka, Y. Shibata, K. Hirose, Anthropogenic radionuclides in the atmosphere observed at Tsukuba: characteristics of the radionuclides derived from Fukushima, Journal of environmental radioactivity 122 (2013) 55-62.

[29] Y. Miyamoto, K. Yasuda, M. Magara, Size distribution of radioactive particles collected at Tokai, Japan 6 days after the nuclear accident, Journal of environmental radioactivity 132 (2014) 1-7.

[30] O. Masson, W. Ringer, a. Mala, P. Rulik, M. Dlugosz-Lisiecka, K. Eleftheriadis, O. Meisenberg, A. De Vismes-Ott, F. Gensdarmes, Size distributions of airborne radionuclides from the Fukushima nuclear accident at several places in Europe, Environmental science \& technology 47 (19) (2013) 10995-11003.

[31] H. Malá, P. Rulík, V. Bečková, J. Mihalík, M. Slezáková, Particle size distribution of radioactive aerosols after the Fukushima and the Chernobyl accidents, Journal of environmental radioactivity 126 (2013) 92-98.

[32] Y. Igarashi, T. Kogure, Y. Kurihara, H. Miura, T. Okumura, Y. Satou, Y. Takahashi, N. Yamaguchi, A review of Cs-bearing microparticles in the environment emitted by the Fukushima Dai-ichi Nuclear Power Plant accident, Journal of environmental radioactivity 205 (2019) 101-118. 
[33] G. Furuki, J. Imoto, A. Ochiai, S. Yamasaki, K. Nanba, T. Ohnuki, B. Grambow, R. C. Ewing, S. Utsunomiya, Caesium-rich micro-particles: A window into the meltdown events at the Fukushima Daiichi Nuclear Power Plant, Scientific reports 7 (2017) 42731.

[34] S. Utsunomiya, G. Furuki, A. Ochiai, S. Yamasaki, K. Nanba, B. Grambow, R. Ewing, Caesium fallout in Tokyo on 15th march, 2011 is dominated by highly radioactive, caesium rich microparticles, arXiv preprint arXiv:1906.00212 (2019).

[35] H. Webster, D. Thomson, The NAME wet deposition scheme, Tech. Rep. Forecasting Research Tech. Report NO. 584, Met Office (2014)

URL https://www.metoffice.gov.uk/research/library-and-archive/publications/science/ weather-science-technical-reports

[36] R. Maryon, D. Ryall, A. Malcolm, The NAME 4 dispersion model: Science documentation, Met Office turbulence and diffusion note 262 (1999) 45

[37] H. Webster, D. Thomson, A particle size dependent wet deposition scheme for name., Tech. Rep. Forecasting Research Tech. Report NO. 624, Met Office (2017).

URL https://www.metoffice.gov.uk/research/library-and-archive/publications/science/ weather-science-technical-reports

[38] J. Feng, A 3-mode parameterization of below-cloud scavenging of aerosols for use in atmospheric dispersion models, Atmospheric Environment 41 (32) (2007) 6808-6822.

[39] J. Feng, A size-resolved model for below-cloud scavenging of aerosols by snowfall, Journal of Geophysical Research 114 (D8) (2009). doi:doi.org/10.1029/2008JD011012.

[40] P. Stier, J. Feichter, S. Kinne, S. Kloster, E. Vignati, J. Wilson, L. Ganzeveld, I. Tegen, M. Werner, Y. Balkanski, et al., The aerosol climate model ECHAM5 HAM, Atmospheric Chemistry and Physics 5 (4) (2005) 1125-1156.

[41] J. Imoto, A. Ochiai, G. Furuki, M. Suetake, R. Ikehara, K. Horie, M. Takehara, S. Yamasaki, K. Nanba, T. Ohnuki, et al., Isotopic signature and nano-texture of cesium-rich micro-particles: Release of uranium and fission products from the Fukushima Daiichi Nuclear Power Plant, Scientific reports 7 (1) (2017) 5409

[42] The Fukushima Daiichi Accident, Non-serial Publications, International Atomic Energy Agency, Vienna, 2015. URL https: //www . iaea.org/publications/10962/the-fukushima-daiichi-accident

[43] R. Ikehara, M. Suetake, T. Komiya, G. Furuki, A. Ochiai, S. Yamasaki, W. R. Bower, G. T. Law, T. Ohnuki, B. Grambow, et al., Novel method of quantifying radioactive cesium-rich microparticles (csmps) in the environment from the Fukushima Daiichi nuclear power plant, Environmental science \& technology 52 (11) (2018) 6390-6398.

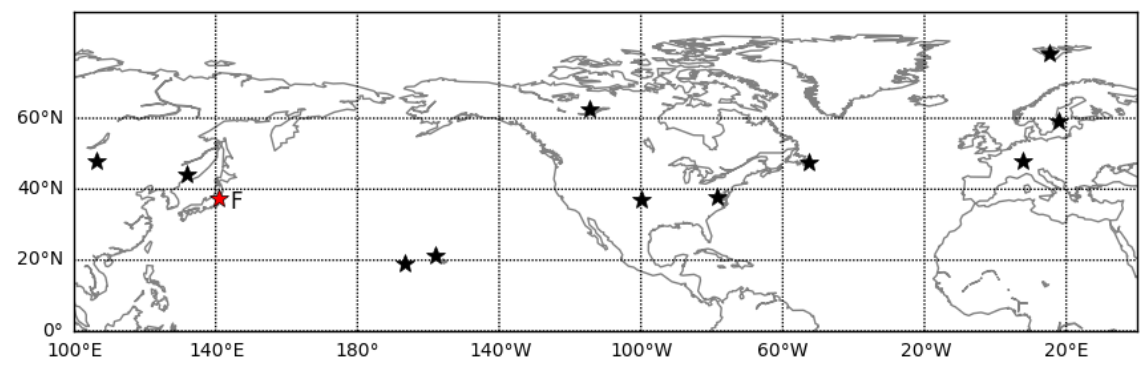

Figure 1: Location of CTBTO measurement sites analysed. Ashland (37.17N, 99.77W), Charlottesville (37.99N, 78.39W), Oahu (21.52N, 157.99W), Schauinsland (47.92N, 7.91E), Spitsbergen (78.23N, 15.39E), Stockholm (59.41N, $17.95 \mathrm{E})$, Ulaanbaatar $(47.89 \mathrm{~N}, 106.33 \mathrm{E})$, Ussuriysk $(44.15 \mathrm{~N}, 132 \mathrm{E})$, Wake Island $(19.29 \mathrm{~N}, 166.61 \mathrm{E})$, Yellowknife $(62.48 \mathrm{~N}, 114.47 \mathrm{~W})$ and St Johns $(47.59 \mathrm{~N}, 52.74 \mathrm{~W})$. The location of Fukushima is shown as red star (and denoted by 'F').

\section{Appendix A. Sensitivity to horizontal and vertical averaging scales}



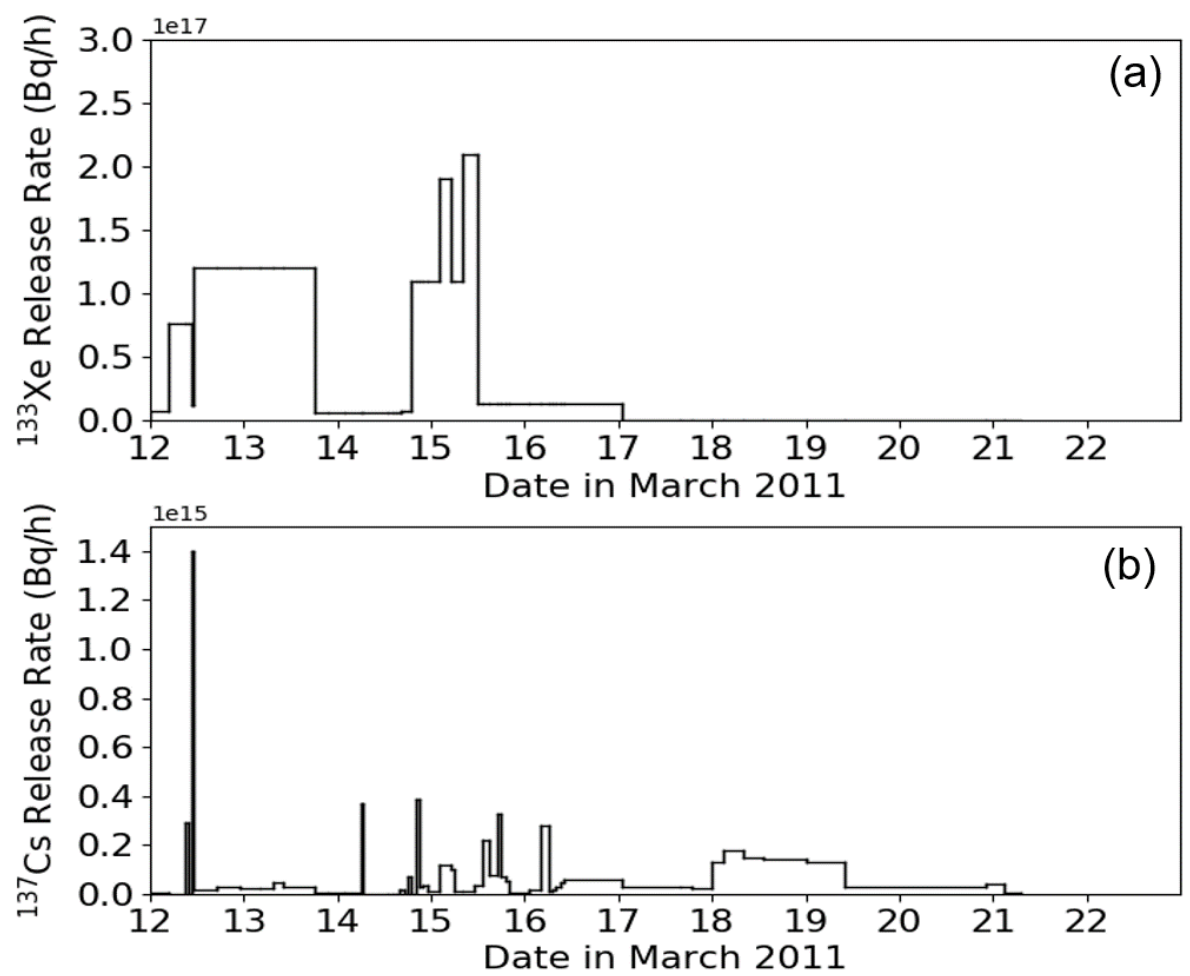

Figure 2: Timeseries of (a) ${ }^{133} \mathrm{Xe}$ released at Fukushima [23] and (b) ${ }^{137} \mathrm{Cs}$ released at Fukushima [26]
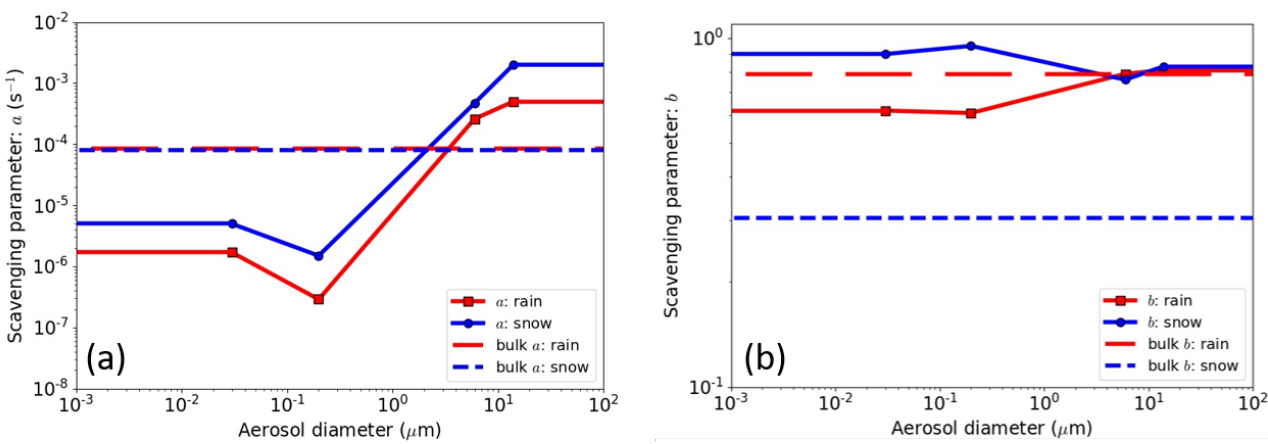

Figure 3: Variation of below-cloud scavenging parameters, (a) $a$ and (b) $b$, with particle diameter [37]. For comparison, the default bulk scavenging parameters are shown. 

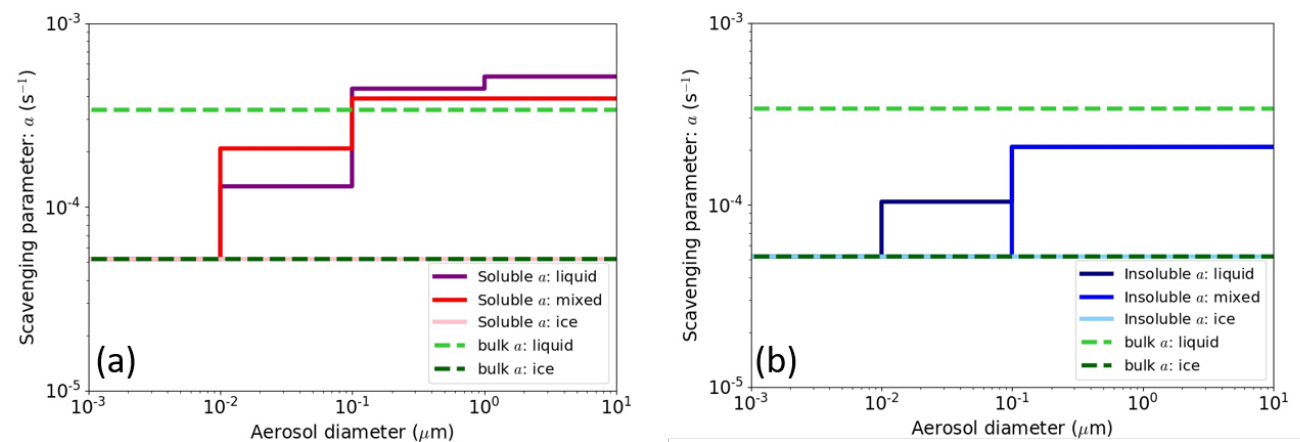

Figure 4: Variation of in-cloud scavenging parameter $a_{i}$ with particle diameter in liquid, mixed and ice phase clouds for (a) soluble and (b) insoluble particles. For comparison, the in-cloud bulk scavenging parameters are shown. In-cloud parameter $b$ is constant at 0.79 for all parameterisations.

\begin{tabular}{|c|c|c|c|c|c|c|c|c|c|c|}
\hline Lat/lon & Depth & 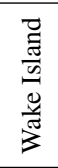 & $\frac{\vec{Z}}{\text { పేँ }}$ & $\begin{array}{l}\frac{0}{\Xi} \\
\frac{\vec{J}}{3} \\
\frac{\bar{a}}{2}\end{array}$ & $\frac{\vec{\Xi}}{\frac{\vec{J}}{\tilde{n}}}$ & 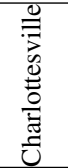 & 兽 & 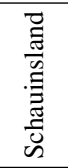 & $\begin{array}{l}\text { E } \\
\text { O } \\
\text { 竞 } \\
\text { O } \\
\text { in }\end{array}$ & 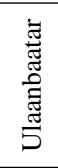 \\
\hline \multicolumn{11}{|c|}{ Correlation } \\
\hline $1^{\circ} \times 1^{\circ}$ & $0-2 \mathrm{~km}$ & 0.52 & 0.74 & 0.08 & 0.62 & 0.34 & 0.25 & 0.32 & 0.49 & 0.31 \\
\hline $1^{\circ} \times 1^{\circ}$ & BL & 0.56 & 0.78 & 0.09 & 0.57 & 0.49 & 0.27 & 0.40 & 0.40 & 0.39 \\
\hline $2^{\circ} \times 2^{\circ}$ & $0-2 \mathrm{~km}$ & 0.53 & 0.74 & 0.06 & 0.65 & 0.36 & 0.19 & 0.29 & 0.54 & 0.44 \\
\hline \multicolumn{11}{|l|}{ RMSLE } \\
\hline $1^{\circ} \times 1^{\circ}$ & $0-2 \mathrm{~km}$ & 14 & 8 & 44 & 8 & 18 & 42 & 8 & 20 & 16 \\
\hline $1^{\circ} \times 1^{\circ}$ & BL & 13 & 7 & 45 & 9 & 18 & 41 & 9 & 20 & 16 \\
\hline $2^{\circ} \times 2^{\circ}$ & $0-2 \mathrm{~km}$ & 14 & 8 & 44 & 8 & 17 & 43 & 9 & 20 & 16 \\
\hline \multicolumn{11}{|l|}{ GMB } \\
\hline $1^{\circ} \times 1^{\circ}$ & $0-2 \mathrm{~km}$ & $1 / 7$ & $1 / 4$ & $1 / 38$ & $1 / 7$ & $1 / 13$ & $1 / 26$ & $1 / 7$ & $1 / 16$ & $1 / 11$ \\
\hline $1^{\circ} \times 1^{\circ}$ & BL & $1 / 7$ & $1 / 4$ & $1 / 38$ & $1 / 8$ & $1 / 13$ & $1 / 25$ & $1 / 7$ & $1 / 16$ & $1 / 11$ \\
\hline $2^{\circ} \times 2^{\circ}$ & $0-2 \mathrm{~km}$ & $1 / 7$ & $1 / 4$ & $1 / 38$ & $1 / 7$ & $1 / 12$ & $1 / 25$ & $1 / 7$ & $1 / 16$ & $1 / 11$ \\
\hline
\end{tabular}

Table A.5: Evaluation statistics for the simulations including bulk particle size distribution described in section 3.2 and Table 1. Lat/lon indicates the horizontal spatial area over which concentrations are calculated. Depth indicates the vertical depth over which concentrations are calculated. 0-2 km simulation concentrations are calculated over the lowest $2 \mathrm{~km}$ of the atmosphere and the BL simulations concentrations are calculated over the boundary layer depth. Statistics calculated for $\log _{10}\left({ }^{137} \mathrm{Cs}\right)$. Grey shading indicate receptors at which the correlation is not significant at the $99 \%$ confidence level, RMSLE is $>10$, GMB $>5$ or GMB $<1 / 5$ 

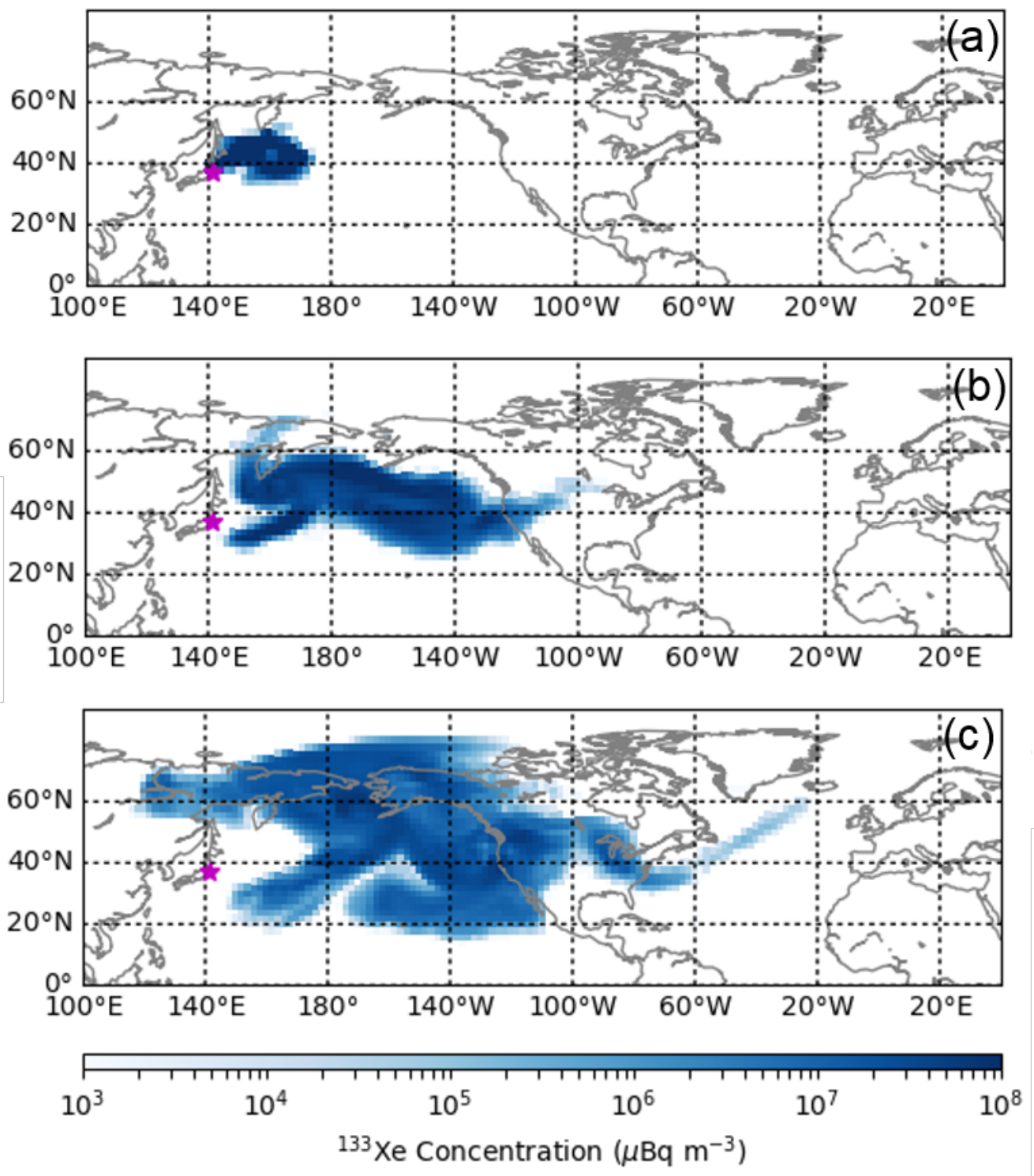

Figure 5: Vertically and temporally averaged $\left(0-2000 \mathrm{~m}\right.$ and 12 -hourly) ${ }^{133} \mathrm{Xe}$ concentrations $\left(\mu \mathrm{Bq} \mathrm{m}^{-3}\right)$. (a). 12UTC on 14 March - 00Z on 15 March, (b) 12UTC on 17 March - 00Z 18 March and (c) 12UTC on 20 March - 00Z 21 March 2011. Magenta star marks the position of the Fukushima Dai-ichi nuclear power plant. 

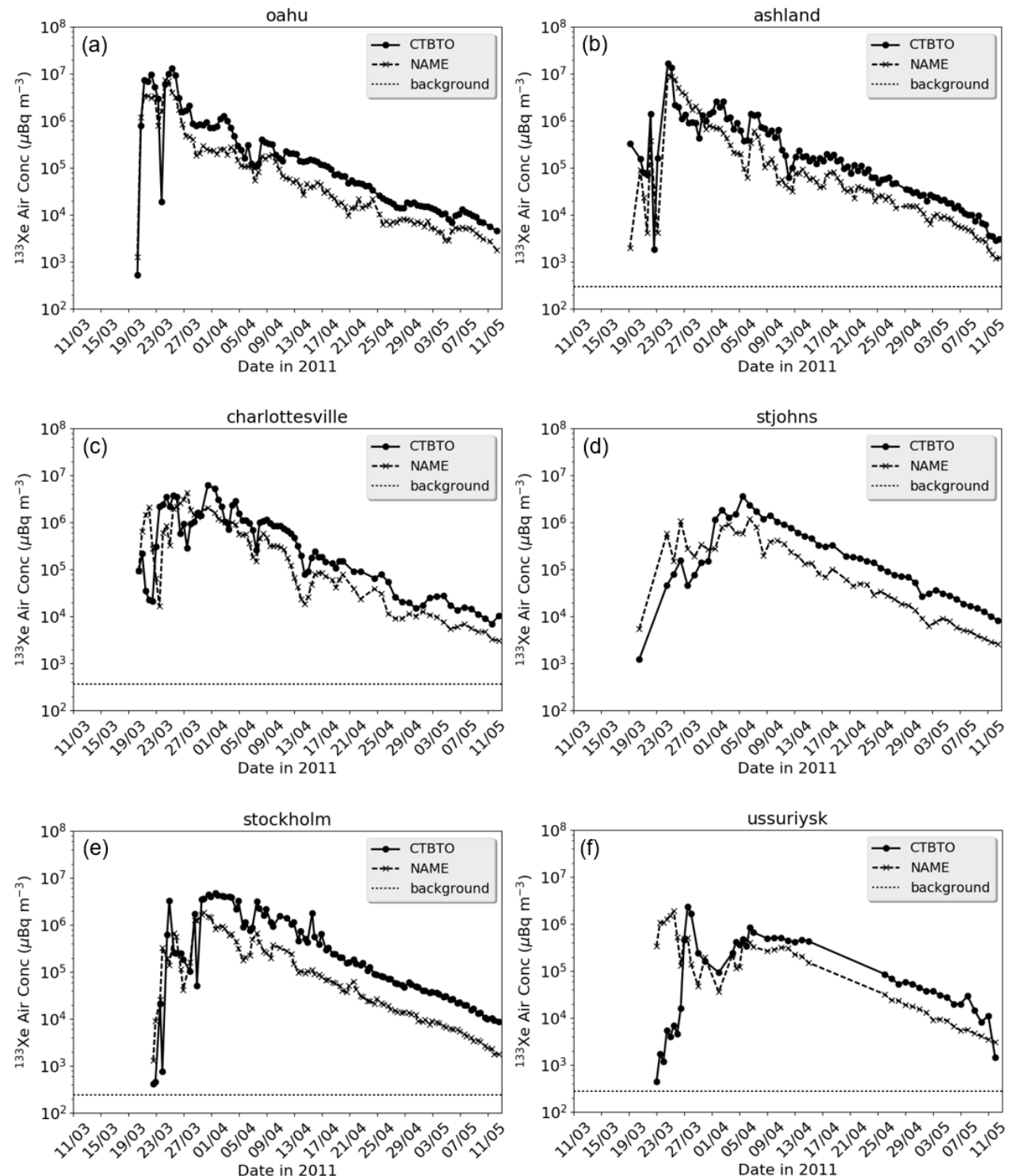

Figure 6: Timeseries of 12-hourly averaged vertically averaged $(0-2000 \mathrm{~m}){ }^{133} \mathrm{Xe}\left(\mu \mathrm{Bq} \mathrm{m}{ }^{-3}\right)$ at (a) Oahu, (b) Ashland, (c) Charlottesville, (d) St Johns, (e) Stockholm and (f) Ussuriysk. CTBTO meaurements (black circles), NAME simulations (black crosses). Background concentration (black dotted). Values are only shown when both observations and NAME concentrations are non-zero. Date labels are day/month. 

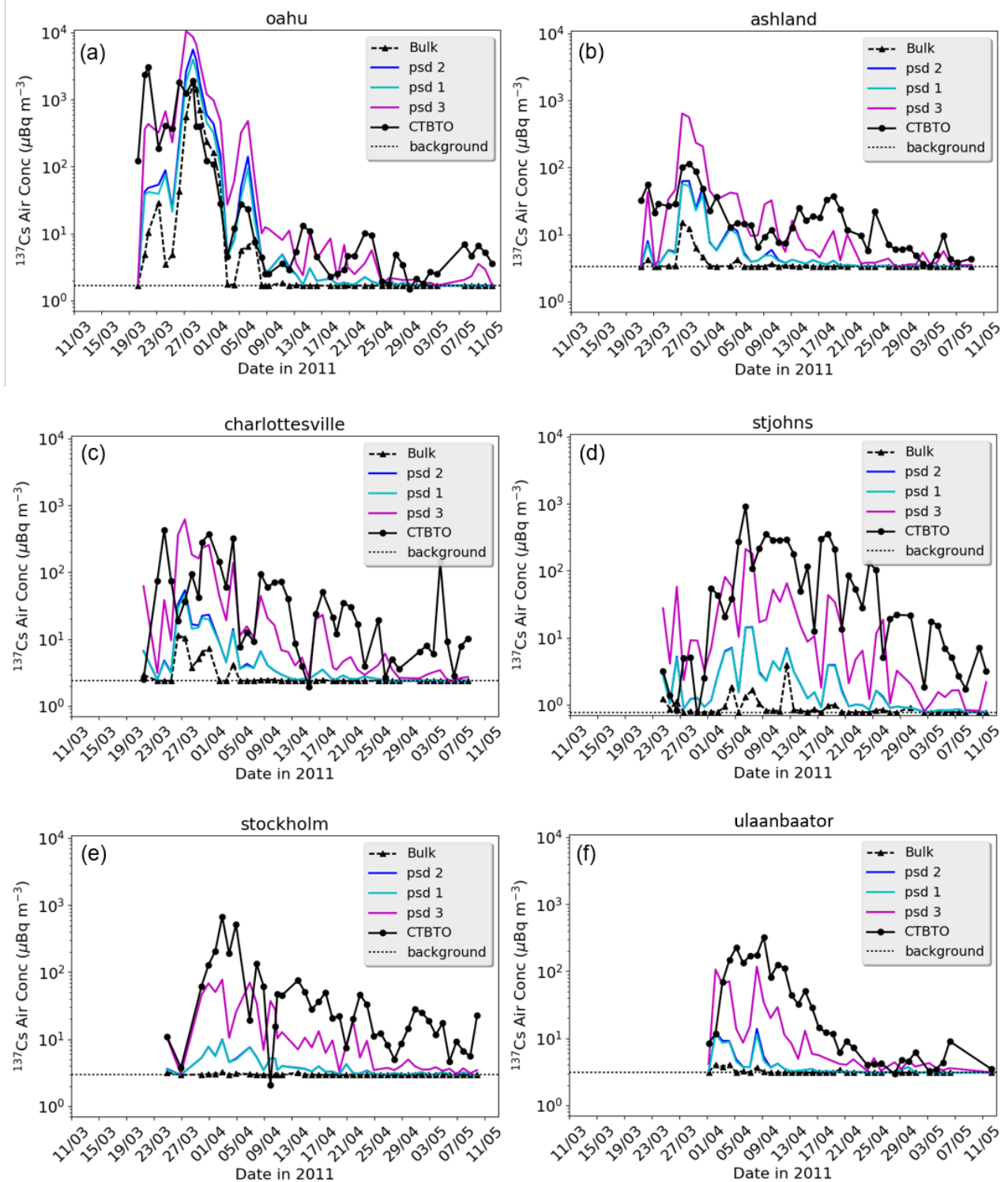

Figure 7: Timeseries of 24-hourly averaged vertically averaged $(0-2000 \mathrm{~m}){ }^{137} \mathrm{Cs}\left(\mu \mathrm{Bq} \mathrm{m}{ }^{-3}\right)$ at (a) Oahu, (b) Ashland, (c) Charlottesville, (d) St Johns, (e) Stockholm and (f) Ulaanbaatar. CTBTO measurements (black circles). NAME simulations using bulk wet deposition parameterisation (black triangles), psd 1 (cyan), psd 2 (blue) and psd 3 (magenta). Background concentration (black dashed). Values are only shown when both observations and NAME concentrations are non-zero. Date labels are day/month. 